\title{
A model for mentoring newly-appointed nurse educators in nursing education institutions in South Africa
}

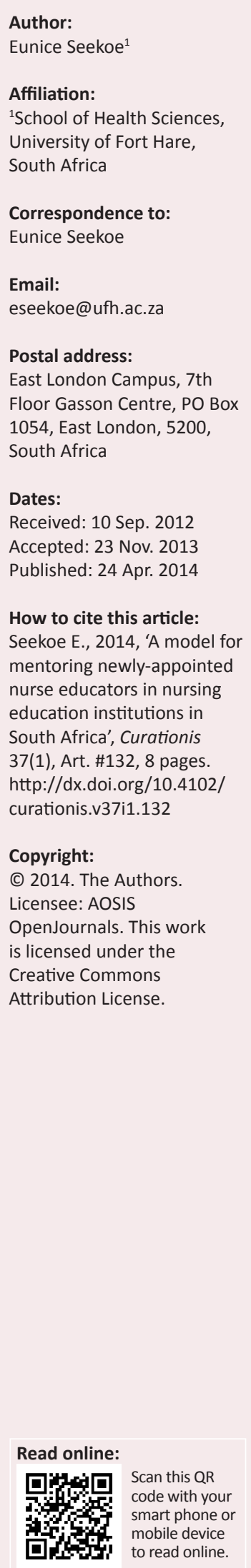

Background: South Africa transformed higher education through the enactment of the Higher Education Act (No. 101 of 1997). The researcher identified the need to develop a model for the mentoring of newly-appointed nurse educators in nursing education institutions in South Africa.

Objectives: To develop and describe the model for mentoring newly-appointed nurse educators in nursing education institutions in South Africa.

Method: A qualitative and theory-generating design was used (following empirical findings regarding needs analysis) in order to develop the model. The conceptualisation of the framework focused on the context, content, process and the theoretical domains that influenced the model. Ideas from different theories were borrowed from and integrated with the literature and deductive and inductive strategies were applied.

Results: The structure of the model is multidimensional and complex in nature (macro, meso and micro) based on the philosophy of reflective practice, competency-based practice and critical learning theories. The assumptions are in relation to stakeholders, context, mentoring, outcome, process and dynamic. The stakeholders are the mentor and mentee within an interactive participatory relationship. The mentoring takes place within the process with a sequence of activities such as relationship building, development, engagement, reflective process and assessment. Capacity building and empowerment are outcomes of mentoring driven by motivation.

Conclusion: The implication for nurse managers is that the model can be used to develop mentoring programmes for newly-appointed nurse educators.

\section{Introduction}

The purpose of the article was to describe the model for mentoring of newly-appointed nurse educators in nursing education institutions in South Africa. In South Africa, nursing education is regulated by the South African Nursing Council (SANC), in accordance with the Nursing Act (No. 33 of 2005) (South Africa 2005) relating to nursing education institutions. The SANC acts as an accreditation and education and training quality assurance body (ETQA) for nursing education (South African Nursing Council 2005:5). Nursing education institutions are approved or accredited by the SANC as nursing colleges (public or private) or as departments or schools of nursing within higher education institutions. Higher education institutions broadened and changed their vision, mission and mandates as a result of changes in economic climate, needs of communities and the knowledge explosion in accordance with the government transformation framework (Büchner \& Hay 1998:20; Council on Higher Education 2004:1; South Africa 2000:2).

Change in nursing education has, in the same way, been brought about by redress of the past inequalities of the education system in South Africa. This change has led to an increase in student numbers with the consequences of multiculturalism, multilingualism and multiracialism, which were not prevalent in the previous higher education system in South Africa (South Africa 2000:2). This growth is not only seen in the student body but also in the academic staff's workload and the need for institutional development, creativity and innovation in teaching and learning (South Africa 2000:2). The increase in student numbers has impacted on the number of newly-qualified nurse educators. Nursing education institutions were challenged to recruit more academic staff members and there was consequently a greater need for the mentoring of newly-appointed nurse educators (NANEs) (South Africa 2000:2). Historically-disadvantaged nurse educators do not have easy access to higher education institutions because of a lack of required competencies. Those who have required qualifications such as Masters degrees find it difficult to climb the ladder of success because of a lack of support and mentoring by more experienced nurse educators. This leads to a shortage of qualified staff of this calibre in higher education (Greyling 2003:8).

In South Africa, nursing colleges are classified as higher education institutions and are expected to comply with the quality requirements of the Higher Education Act No. 101 of 1997 (South Africa 
1997) and the Nursing Act No. 33 of 2005 (South Africa 2005). However, although the management of nursing colleges falls under the control of the Department of Health in nine different provinces, the academic quality control is regarded as being the responsibility of the universities. The nurse educators are appointed by the Department of Health and their conditions of service are controlled by the human resources department of their respective provinces. Nurse educators at universities are appointed by their respective universities and their conditions of service are controlled by the human resources departments of their universities. Nurse educators in both environments are oriented in and accustomed to the institutions through induction programmes offered by their institutions. Neither environment has sufficient mentoring programmes (Greyling 2003:8). Nurse educators appointed at universities have an added responsibility of being moderators for the theoretical and clinical teaching programmes offered by the nursing colleges in order to ensure quality teaching. The educators at universities are also expected to have more expertise than those at nursing colleges (Booyens 1998:381; Muller 2002:261). Nursing colleges are still affected by the same problems that characterise higher education in South Africa, such as the need to ensure quality and the increase in student numbers, which leads to an increase in the workload of nurse educators. It is, therefore, important for all efforts directed at improving the conditions and quality of education in higher education to apply to all colleges of nursing as well. Nurse educators at colleges and universities need to be mentored by their senior nurse educators in order to ensure adaptation to the institutional culture as well as academic and career success (South Africa 2000).

There is a lack of support for the NANEs in higher education institutions, which exacerbates the high staff turnover. Thirty percent of these lecturers leave the institution within the first five years, which is tremendously costly, in terms of both human and economic resources (O'Brien 2003:10). To be successful in their vision and/or mission of teaching students the nurse educators must focus on improving the quality of their schools and/or departments, which can be accomplished through senior nurse educators mentoring their newly-appointed and junior colleagues (English, Bonaguro \& Madison 2005:296). This can help reduce the rate of attrition and improve the nurse educators' skills and confidence in their work. It is important that nurse educators be effectively capacitated and supported (Waters et al. 2003:516). Lack of mentoring leads to various workplace problems for NANEs.

\section{Problem statement}

In order to achieve the goal of transformation, as is expected of higher education institutions, nurse educators must be supported (South Africa 2000: 2). Institutions of higher education in nursing do not have mentoring programmes suitable for nurse educators (Greyling 2003:8). Nurse educators receive induction, which is conducted for all newlyappointed staff, but this does not put emphasis on nursing educators' needs (Booyens 1998:381; Muller 2002:261). On their first day of work, nurse educators mainly receive orientation about the physical layout of the school and/or department and its policies. In institutions where mentoring is practised effectively, mentors who are assigned to NANEs convey their wisdom to their mentees. Mentors are experienced leaders who act as friends and their goal is to create a safe context for academic growth and support for the mentees $\left(\mathrm{O}^{\prime}\right.$ Brien 2003:10). Mentoring is needed in order to build the capacity of nursing education institutions.

There seems to be no sufficient provision for capacity building in relation to actual teaching, research and community development (Büchner \& Hay 1998:2). Research output is rated highly at South African higher education institutions and, consequently, academic writing and publications in accredited journals are important criteria for appointment and promotion. The research function of universities has escalated in size and strength (Büchner \& Hay 1998:2). Funding formulae of higher education institutions are based on research output and throughput rates. Therefore, teaching and learning to increase the number of postgraduates in order to increase throughput rates is an additional challenge for academic staff members (Büchner \& Hay 1998:20; South Africa 2000:2). Higher education is characterised and challenged by the complexity of content and quality regulation policies, unmet mentoring needs of NANEs and the need to recruit and retain quality nurse educators who can cope with the challenges of higher education (Büchner \& Hay 1998:20; South Africa 2000:2). Reyes (2003) supports this idea by indicating that mentoring is a much-needed career development opportunity that socialises NANEs within their higher education institutions whilst simultaneously developing the skills and behaviour of dynamic leaders.

The nature of the problem was revealed by a survey conducted by the researcher which indicated the lack of mentoring programmes at schools and/or departments of nursing at higher education institutions in South Africa. Fifteen (83\%) of the $18(100 \%)$ universities responded negatively to the inquiry about the availability of mentoring programmes in their institution; the line managers indicated that such mentoring programmes did not exist. The head of one school of nursing responded telephonically and indicated that she was in the process of developing a programme for the entire Faculty of Health Sciences. Eleven (28\%) of the $31(100 \%)$ nursing colleges responded in writing to the question about the availability of mentoring programmes at their institutions. All 11 nursing colleges indicated that they did not have a programme of that nature. Some of the heads of schools and/or departments stated in writing that staff members were exposed to the induction programmes of their universities conducted by their Human Resources Departments together with all other newly-appointed staff. There are no mentoring programmes at these institutions especially for nurse educators.

From the problem statement and the results of the survey it can be deduced that certain needs are apparent amongst NANEs in nursing education institutions in South Africa. The development of a model to mentor NANEs in nursing 
education institutions in South Africa, as a possible solution to the highlighted problems, was needed. Thus, the following question can be asked: 'What model can be developed to mentor newly-appointed nurse educators in nursing education institutions in South Africa?'

\section{Aim of the study}

The aim of this study was to describe the model for mentoring NANEs in nursing education institutions in South Africa.

\section{Research objectives}

The objectives of this study were to develop a model for mentoring NANEs in nursing education institutions in South Africa and to describe the model for mentoring NANEs in these institutions.

\section{Definition of key concepts}

Mentoring is when a senior member of an organisation takes on a more junior colleague or may occur between peers, providing a variety of developmental functions. In this study, mentoring is an interactive, reflective, participatory process of relationship building, engagement and development between mentor and mentee during which the former develops and evaluates the achievement of specific development needs in order to achieve the outcome of empowerment and capacity building with regard to specific competencies (Seekoe \& Arries 2011:26).

Nursing education is the process whereby learners are guided, assisted and provided with the means which enable them to learn the art and science of nursing so that they can apply this to the nursing care of people who need such care. The ultimate aim of nursing education is the development of highly-skilled professional practitioners as registered nurses (Mellish, Brink \& Paton 2009:20). For the purpose of this study, a nursing education institution is a public nursing college or is a department or a school of nursing within universities in South Africa (Seekoe \& Arries 2011:26).

A newly-appointed nurse educator (mentee) is a professional nurse who holds a nursing education qualification and is registered with the SANC with that qualification, or is a professional nurse who is registered with the SANC as a general nurse and is in her or his first five years of appointment at a nursing education institution (Mellish et al. 2009:20). For the purpose of this model, a nurse educator is referred to as a mentee who participates in an interactional relationship with a mentor in order to have their mentoring needs met (Seekoe 2009:195).

A model: according to Walker and Avant (2010:126), a model is described as a symbolic representation of empirical experience. In this study, a mentoring model is practice based on the philosophy of reflective practice, competency-based practice and critical social learning theories (Seekoe 2009:186).

\section{Research method and design}

A qualitative and theory construction design (Walker \& Avant 2010:131) was suitable for the development of the model and was thus used. The process of model development was based on literature review and the findings of analysed needs of NANEs. The analysis of essential concepts was done further through an exploratory factor analysis. The conceptual framework for the mentoring model was developed wherein reasoning strategies of analysis, synthesis, derivation, deduction and induction were applied (Chinn \& Kramer 1995:152; Walker \& Avant 2010:20), including the experiential knowledge of the researcher (Seekoe 2013:142 ).

\section{Ethical considerations}

Ethical considerations, as set out by the Democratic Nursing Organisation of South Africa (DENOSA 1998) in its ethical standards for nurse researchers, were ensured through requesting that participants sign consent and by keeping the participant's information confidential. To ensure privacy and anonymity, the participants and names of institutions were not required in the questionnaires. Self-determination was ensured by allowing participants to withdraw from the study at any time without fear of being punished. Justice was ensured through selecting and treating participants fairly and equally during the study.

\section{The process of model development}

The conceptualisation framework for the model focused on the context, content and process (Dickoff, James \& Wiedenbach 1968:430) and the theoretical domains that influenced the model. Ideas from different theories were borrowed and integrated with literature. The 'context' represented the nursing education practice environment. The 'intervening factors' are the legal, professional, ethical and practice working environment, healthcare and education of nurses. 'Content' refers to the theory of the research domain acquired through literature study on mentoring, the findings of the mentoring needs analysis and essential mentoring needs (conceptual framework); and the 'process' refers to the mentoring needs in nursing education institutions.

\section{Definition and classification of concepts}

Identification of concepts was done during literature study and analysis of the descriptive data. Identification of essential needs and concept analysis was done through the performance of exploratory factor analysis where different inferential statistical tests were done and essential mentoring needs were identified. Conceptual meaning was created by considering all sources of literature and experiences related to the concepts under study (Chinn \& Kramer 1995:75). Classification of concepts was achieved by using the survey list described by Dickoff et al. (1968:434). Identified concepts were structured within the parameters of integrating theories and models such as stage/identity and transformation theory, contextual dialectical theory, motivation theory and interactional learning theory. Models that were integrated included the critical reflective model (Stuart 2000:700), the three-part dimension model (Schrodt, Cawyer \& Sanders 2003:1) and the competency-based model (Wood 2005:39). The survey list of agent, recipient, terminus, framework and procedures was 
used to clarify concepts. The researcher thereafter classified concepts and determined relational statements.

At this level of theory development, concepts were seen in relation to each other and represented a higher level of complexity. Relationship statements were formulated in order to provide links between and amongst concepts. Tentative relationships were identified. The nature and characteristics of the relationships were discussed. According to Chinn and Kramer (1995:14), the relationship within a theory that creates meaning and impacts understanding often links multiple concepts in a loose structure. These structures emerge from relationships in the theory. The relationship between major or central concepts was clear and individual concepts were structured so as to create greater clarity (Chinn \& Kramer 1995:117)

In this study, the context will represent the (framework), the role players (agents and recipients), the purpose (terminus), the process (procedures) and the dynamics (cognitive dissonance around mentoring). The central concepts in the context of nursing education requiring competency development (stakeholders), dependent concepts (the purpose and process of mentoring) and their related constructs will be discussed under each main concept in the model. This will indicate evidence of logical reasoning and consistency throughout the study.

\section{Assumptions of the model}

The theoretical framework of this model is based on the philosophy of reflective practice, competency-based practice and critical social learning theories (Stevens 2000:20). The assumptions in relation to stakeholders, context, mentoring, process, outcome and dynamics will be described.

\section{Assumptions related to the context}

Mentoring occurs in a context that is multidimensional and highly interactive in nature. In the context of higher education, the mentee is expected to perform according to the quality requirement structures in order to ensure that the political needs of a country - increased numbers of graduates with knowledge and skills to benefit the economy - are met. The legal context includes requirements, where the mentee is expected to ensure quality in teaching, learning and research. The nursing education institution expects the mentee to function according to the performance management policies in order to achieve its vision, mission, values and strategy. At the school and/or departmental level the mentee is expected to teach, research and engage in the community at required specific competencies within the physical and psychosocial dimensions of the mentoring process.

\section{Assumptions related to stakeholders (mentor and mentee)}

The mentor and mentee are believed to be holistic beings that function in a psychosocial and cultural environment. They both interact through a participative and interactional relationship to which they commit and where the mentee states their mentoring needs. The mentor displays characteristics that should ensure the success of the relationship, such as acting as a peer and colleague, being available and being a motivator, role-model and capacity builder, which means that the mentee should then feel comfortable interacting with their mentor in a dialogical manner (Wood 2005:39).

\section{Assumptions related to the process of mentoring}

Mentoring is believed to be a purposeful directed process of competency development, empowerment and capacity building within an interactive participatory relationshipbuilding process of inquiry, interpretation and dialogue. Throughout the mentoring relationship, a mentor facilitates the ability to inquire and seek new knowledge in order to improve the mentee's performance. A mentor also assists a mentee in developing the skills required to both identify and interpret the requirements and expectations of higher education using reflective practice and by applying constructivism through active exploration. Acquisition of skills of self-inquiry is done under the control of a mentor - a process called scaffolding. The mentor serves as a role model to the mentee. The mentee is allowed to reflect on their practice and to develop learning abilities by constructing a portfolio of evidence.

\section{Assumptions related to the outcome of mentoring}

The purpose of mentoring is capacity building, empowerment and development of competencies in order for the mentee to function effectively in their own environment. It is achieved through participatory interaction between a mentor and mentee.

\section{Assumptions related to the dynamic of mentoring}

The energy source of this model (see Figure 1) is that motivation and commitment are important for the success of mentoring. Empowerment and capacity building are important for adaptation to a new environment.

\section{Description of the model}

A model for mentoring NANEs in nursing education institutions in South Africa will be described according to its structure, showing the context, stakeholders, interactive participatory relationship, mentoring process, outcome, dynamics and its evaluation.

\section{Structure of the model}

\section{The context}

The mentoring model is multidimensional and complex in nature. Various dimensions of the context are indicated amongst the macro (higher education), meso (institution) and micro (department of nursing) levels. The three levels of context are linked and have important influences on the practice of the mentee. The macro context has legal, 


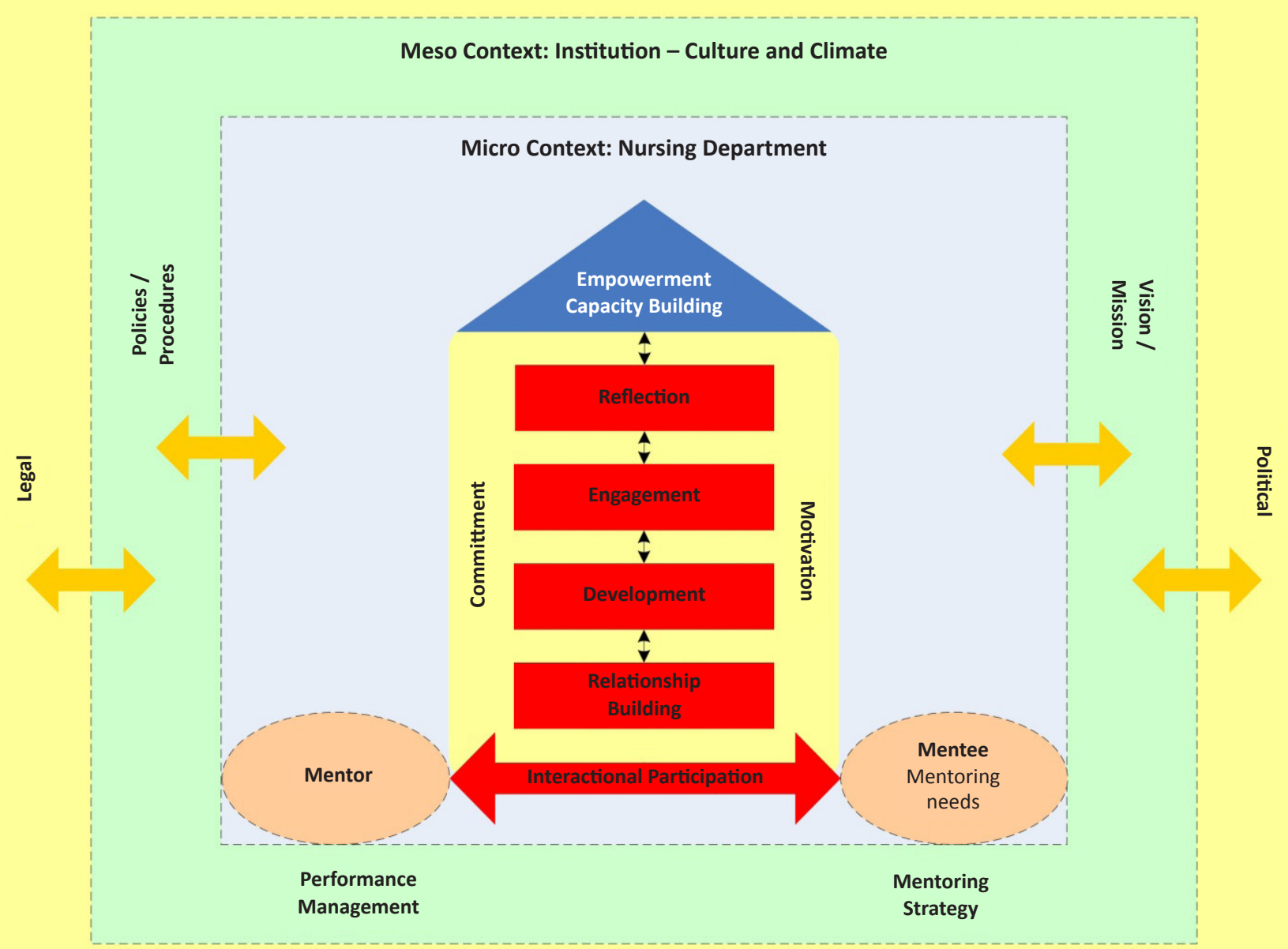

FIGURE 1: Mentoring model.

political and professional framework facets characterised by various legislation that puts demands on the institutions and mentoring of staff. All the structures require competent nurse educators who can produce skilled graduates who will ultimately be employed in the healthcare industry in order to improve service delivery. Mentoring serves the purpose of developing the required competencies of the mentee in order to increase performance which can, in turn, lead to retention. Analysis and clarification of the main concepts of empowerment and capacity building in order to develop competencies and increase the performance of the mentee in the multidimensional context of higher education give the outcome, structure and the process of the model. The environment of the practice of nursing education is influenced by complex factors impacting on one another. The context of higher education impacts on the institutional processes and procedures within which the mentor and mentee function in their relationship.

The meso context (higher education institution) depicted in this model refers to the higher education institution such as the university or nursing college where the mentee is employed. It is made up of elements such as vision, mission and values accompanied by strategy and strategic goals that impact on the mentoring process within that specific institution, as well as performance management strategies and mentoring strategies by which the mentoring performance of both the mentor and mentee are measured. The institution has a unique culture to which the mentee has to adapt and develops governance structures which ensure quality in its delivery of services. The department of human resources is tasked with the responsibility of ensuring that staff increase performance in order to achieve strategic goals. Mentoring is utilised to develop the competencies of the mentee, so that they become competent in teaching, research and community development.

The micro context (department of nursing) in this model refers to the time-spatial situation within which the mentor and the mentee find themselves. This could mean, for example, a nursing department and the relationship between the mentor and mentee. The key stakeholders at this level 
are the mentor and the mentee. The culture of the nursing department is unique and may be strange to the mentee. The environment itself is physical and psychosocial in nature. The relationship between the mentor and the mentee is interactional and participatory and important in that it is central to the success of the mentee in higher education. A mentor has the role of responding to the needs of mentee, which they do through the process of relationship building, engagement, development and reflection. This process leads to the outcomes of mentoring which are capacity building, empowerment and competency development. The mentee has needs which are stated in the empirical phase of the study and he or she is an active participant in the relationship in that these needs are communicated to the mentor. Both mentor and mentee commit to the relationship.

\section{Stakeholders}

Stakeholders are individuals who have a participatory role in a project or a process and, in this case, both the mentor and mentee are important.

\section{Mentor}

A mentor is one of the important stakeholders in the success of mentoring and has the role of ensuring that the mentee is empowered, capacitated and academically competent in order to succeed in higher education. A mentoring role is carried out within a participatory interactional relationship with the initial stages of getting established, performing and ending with the mentee. A mentor achieves the outcomes of mentoring through relationship building, development, engagement and reflection. When the two role players work together cooperatively the relationship becomes closer and more successful.

\section{Mentee}

A mentee is the most important stakeholder, participating in an interactional relationship with a mentor in order for their own mentoring needs to be met.

\section{Needs}

The needs of a mentee are determined based on the empirical data and are grouped into structure, stakeholder, process needs and outcome needs within a participatory interactional relationship throughout the stages of relationship building, development, engagement, reflection and evaluation. The mentee's needs are based on the outcome - such as being empowered, having capacity and feeling competent at the end of the mentoring period. The mentee shows responsibility whilst participating in a mentoring relationship through request and being available to participate in dialogue with a mentor. A mentor challenges the mentee through questions so as to stimulate thinking as a reflective practitioner.

\section{Interactive participatory relationship}

Interactional participatory relationship implies that the mentor acts as a peer and that both depend on each other. The success of the relationship is indicated by the development of the mentee's competencies and is demonstrated by a free exchange of ideas between the mentor and mentee. The mentee is engaged through strategies of information sharing, support and benefits.

\section{The mentoring process}

Mentoring is an interactive participatory reflective process of relationship building and engagement between the mentor and the mentee, during which the former develops and evaluates the achievement of specific development needs in order to achieve the mentoring outcomes through reflective practice. The mentor drives the process of mentoring through a sequence of activities such as building the relationship, development, engagement and reflective practice until mentoring outcomes, such as empowerment and capacity building to develop required competencies, are achieved.

\section{Relationship building}

Relationship building is when the two stakeholders meet and agree to work together toward achieving a mentoring outcome. The relationship develops through stages of initiation, getting established, performing and, ultimately, ending. The initial stage of relationship building starts immediately after induction and is followed by concerns, observation, common characteristics, abilities or recognition of shared values. This stage is identified by signs of carefulness, uncertainty, avoidance of conflict and seeking direction from the mentor. Strategies for managing the stage are closeness and reciprocity, reaching agreements and self-awareness. The stage continues with the signing of a mentoring agreement covering the ground rules and expectations, as well as the frequency of meetings throughout the probation period for whatever period is determined by the institution.

\section{Development}

Development means growth, advancement and improvement in the knowledge, skills and attitude of the mentee in higher education. This is the second stage of getting established, characterised by testing the ground and learning their strengths and weaknesses. The qualities of this stage are conflict, power struggle, criticism and challenge. Strategies of success at this stage are a mentoring strategic plan, observation participation and development according to areas of a job description and the use of consultation sessions. The mentor reaches out to the mentee through counselling and encouragement, ultimately becoming a source of psychological support.

\section{Engagement}

Engagement is the third stage, taking place when the mentor acts as a role model, communicates, acts as a change agent, empowers, leads, guides and focuses on the mentee's performance. This is a stage of working and training, where each stakeholder accepts one another's weak points, demonstrates a willingness to share knowledge, gives input creatively and is fully committed to the process. There is 
mutual trust and respect for each other's competence, as well as honest sharing. The mentor engages and challenges the mentee with scenarios and asks questions that are related to practice, identifies weaknesses and offers constructive feedback and support.

\section{Reflective process}

This is the final stage of higher order construction where there is evidence that a mentor has developed the mentee through being an independent practitioner, communicator, decision maker, problem solver, networker, change agent and a reflective practitioner with regard to their academic functions (research, article writing, conference presentations and teaching, learning and assessment). The strategies for this stage are making sure that the mentee is capacitated and committed to self-inquiry, uses portfolios of evidence, a reflective journal and diary, has been introduced to power structures and networks, manages change and acts as a reflective practitioner.

\section{Assessment}

A mentor uses constructivism to assist the mentee to learn through active exploration and to build new knowledge on the present context of social knowledge of interaction between a mentor and mentee. Acquisition of skills is achieved when a mentee develops required skills through interaction and support by the mentor. This development of an individual's appropriate knowledge and skills is developed until the mentee is in control of them - a process called scaffolding. A mentor carries this role throughout the mentoring relationship.

\section{Mentoring outcome}

The outcome of a mentoring relationship is the development of the required competencies characterised by the promotability of the mentee, which is achieved through capacity building and empowerment. Strategies for capacity building are exposure, support and training, whilst empowerment is achieved through networks, hierarchies and professional associations.

\section{Dynamics}

The driving factor is motivation. In addition, empowerment and capacity building are key to the success of mentoring.

\section{Evaluation of the model}

The model was evaluated in accordance with the guideline criteria for model evaluation laid down by Chinn and Kramer (1995:75) which answered questions as to its clarity, simplicity, generality, accessibility and importance. The model was also evaluated through presentations at national and international conferences and doctoral committees. The researcher used a self-reflective questionnaire in order to evaluate the model under the guidance of expert promoters throughout the study.

\section{Limitations}

This research had some limitations in that data from the nursing colleges were not adequate enough to represent the population because of a poor response from the authorities in terms of permission for data collection.

\section{Recommendations}

For the practice of nursing education: There is a need to test the guidelines for the operationalisation of the model in the practice of nursing education at universities and nursing colleges. There is also a need for the development of mentoring programmes in nursing education institutions in order to test the application of the model.

For research: It is recommended that a mentoring programme be implemented in order to increase research skills and scholarship in nursing education institutions.

\section{Conclusion}

The design and assumptions of the model were discussed, followed by a description of structure. Mentoring takes place in a multidimensional context with three levels: macro (legislation, framework and ethical), meso (governance, strategic, quality assurance and performance-based) and micro (process, competency and stakeholders). The macro level is legal and ethical and is a framework, whilst the meso level is institutional and the micro level is more operational at the school and/or departmental level. Mentoring takes place in a process of relationship building, engagement, development, self-inquiry and reflection. The most important role players are the mentor and the mentee. They relate in an interactive and participative relationship. The outcome of mentoring is empowerment and capacity building in order to develop the competencies of the mentee, which will ultimately increase competencies in higher education.

\section{Acknowledgements}

My sincere gratitude goes to the South African research funding organisations such as the National Research Foundation (NRF) and the Medical Research Council (MRC) with regard to their funding for this study. The UNEDSA Project, funded by Atlantic Philanthropy, is acknowledged for funding to publish this article. I acknowledge the reviewers for giving constructive feedback which contributed to the quality of this publication, as well the participating nurse educators at nursing education institutions in South Africa for responding to the questionnaires and providing support during data collection.

\section{Competing interests}

The author declares that she has no financial or personal relationship(s) which may have inappropriately influenced her in writing this article. 


\section{References}

Booyens, S.W., 1998, Dimensions of nursing management, 2nd edn., Juta Academic Publishers, Kenwyn.

Büchner, J. \& Hay, D., 1998, 'Staff induction: Establishing mentorship programmes for academic staff in South African institutions of higher education', South African Journal of Higher Education, 12(3), 19-25.

Chinn, P.L. \& Kramer, M.K., 1995, Theory and nursing: a systematic approach, 4th edn., Mosby Year Book, St. Louis, MI.

Council on Higher Education, 2004, Criteria for programme accreditation, The Council on Higher Education, Pretoria.

Democratic Nursing Organisation of South Africa, 1998, Position statements: ethical standards for nurse researchers, South Africa.

Dickoff, J., James, P. \& Wiedenbach, E., 1968, 'Theory in a practice discipline. I. Practice oriented theory', Nursing Research, 17(5), 415-435. http://dx.doi.org/10.1097/ 00006199-196809000-00006

English, G., Bonaguro, J. \& Madison, S., 2005, 'Existing abilities and the perceived importance of skill development', American Journal of Health Education, 36(5), 295-301. http://dx.doi.org/10.1080/19325037.2005.10608199

Greyling, L., 2003, Promoting high quality performance through mentoring: a programme for higher education, Johannesburg, Rand Afrikaans University, viewed 15 January 2014, from http://uwf.edu/cdedev/IUTweb10/docs/model_manuscript.doc

Mellish, J.M., Brink, H. \& Paton, F., 2009, Teaching and learning: the practice of nursing, 5th edn., Heinemann Publishers, Johannesburg.

Muller, M.E., 2002, Nursing dynamics, 3rd edn., Heinemann Ltd, Sandown.

O'Brien, L., 2003, 'Mentors: One solution to high attrition rates', Australian Nursing Journal, 10(11), 37.

Reyes, A., 2003, 'The relationship of mentoring to job placement in school administration', NASSP Bulletin, 87(635), 45-64. http://dx.doi.org/10.1177/019263650308763505
Schrodt, P., Cawyer, C.S. \& Sanders, R., 2003, 'An examination of academic mentoring behaviours and new faculty members' satisfaction with socialization and tenure and promotion processes', Communication Education, 52(1), 17-29. http://dx.doi. and promotion processes', Comm
org/10.1080/03634520302461

Seekoe, E., 1999, 'Development, implementation and evaluation of a problem-based learning programme for first year nursing students', unpublished Masters dissertation, Faculty of Health Sciences, School of Nursing, University of the Orange Free State, Bloemfontein.

Seekoe, E., 2013, 'A conceptual framework for a mentoring model for nurse educators', African Journal for Physical, Health Education, Recreation and Dance, 19, Supplement 1, 142-151.

Seekoe, E. \& Arries, E., 2011, 'A South African perspective of mentoring needs for newly appointed nurse educators', in L. Makondo (ed.), 2011, Academic staff mentoring, curriculum change and client perceptions in higher education, Vol. 1(1), pp. 26-45, University of Fort Hare Research Book Series.

South Africa, 1997, Higher Education Act, No 101 of 1997, Government Printers, Pretoria.

South Africa, 2000, 'Aspects of the work of the teacher committee on teacher education system', National Plan for Higher Education, Government Printers, Pretoria.

South Africa, 2005, Nursing Act, No 33 of 2005, Government Printers, Pretoria.

Stevens, K.R., 2000, 'Mentoring on the cutting edge', Reflections on Nursing Leadership, 26(3), 31-32, 46.

Stuart, J., 2000, 'Models of teacher education', unpublished Masters thesis, Faculty of Education, University of Johannesburg.

Walker, L.O. \& Avant, K.C., 2010, Strategy for theory construction in nursing, 5th edn., Prentice Hall International (UK) Ltd, London.

Waters, D., Clarke, M., Ingall A.H. \& Dean-Jones, M., 2003, 'Evaluation of a pilot mentoring programme for nurse managers', Journal of Advanced Nursing, 42(5), 516-526. http://dx.doi.org/10.1046/j.1365-2648.2003.02651.x

Wood, A.L., 2005, The importance of principals: site administrators' roles in novice teacher induction, American Secondary Education, 33(2), 39-62. 